\title{
Blood glucose monitoring
}

National Diabetes Information Clearinghouse (NDIC)

\section{Definitions}

Diabetes

Defined by National Diabetes Information Clearinghouse (NDIC)

Blood glucose level

Defined by National Diabetes Information Clearinghouse (NDIC)

\section{Blood glucose meter}

Defined by National Diabetes Information Clearinghouse (NDIC)

\section{Source}

National Diabetes Information Clearinghouse (U.S.). (2009). The diabetes dictionary. [Bethesda, Md.]: U.S. Dept. of Health and Human Services, National Institutes of Health, National Institute of Diabetes and Digestive and Kidney Diseases, National Diabetes Information Clearinghouse.

Checking blood glucose levels by using a blood glucose meter or blood glucose test strips that change color when touched by a blood sample in order to manage diabetes. 